\title{
Mineralocorticoid Receptor Antagonists in End-Stage Renal Disease: Efficacy and Safety
}

\author{
Andrew S. Bomback \\ Department of Medicine, Division of Nephrology, Columbia University College of Physicians and Surgeons, \\ New York, NY, USA
}

\section{Key Words}

Aldosterone $\cdot$ Spironolactone $\cdot$ Eplerenone $\cdot$ Hyperkalemia

\begin{abstract}
Mineralocorticoid receptor antagonists (MRAs) that block aldosterone's effects on both epithelial and non-epithelial receptors have become a mainstay of therapy for chronic heart failure. Given that cardiovascular events remain the leading cause of death for patients with end-stage renal disease (ESRD), the question of whether these MRAs can be employed in dialysis patients arises. This review summarizes the rationale for blocking aldosterone in patients with chronic and end-stage kidney disease and surveys the data on both the efficacy and safety of using MRAs in the ESRD population. A small but growing body of literature suggests that use of MRAs by ESRD patients is associated with lower blood pressure, reduced left ventricular (LV) mass, and improved LV ejection fraction. Recently, a large randomized trial found an overall 3-year mortality rate of $6.4 \%$ in ESRD patients on spironolactone $25 \mathrm{mg}$ daily vs. $19.7 \%$ in ESRD patients on no MRA therapy $(p=0.002)$, without a significantly increased risk of hyperkalemia.

(c) 2016 S. Karger AG, Basel
\end{abstract}

\section{Introduction}

Interruption of the renin-angiotensin-aldosterone system (RAAS) with angiotensin-converting enzyme (ACE) inhibitors and angiotensin receptor blockers (ARBs) has become a leading strategy in slowing the progression of chronic heart and kidney disease. In the last two decades, mineralocorticoid receptor antagonists (MRAs) that target aldosterone have emerged as important additive therapies in treating chronic heart and kidney disease. Indeed, spironolactone and eplerenone, given in combination with ACE inhibitors or ARBs, are now standard treatments in managing congestive heart failure and have become increasingly used in the care of proteinuric CKD patients. As cardiovascular disease remains the leading cause of death among patients with end-stage renal disease (ESRD), the logical question is whether MRAs will be able to show equally impressive performance in the ESRD population.

\section{Rationale for Aldosterone Blockade in ESRD}

Numerous animal studies have shown that despite RAAS blockade with ACE inhibitors or ARBs, aldosterone infusion leads to profound cardiovascular and renal

\section{KARGER}

E-Mail karger@karger.com www.karger.com/bpu
(C) 2016 S. Karger AG, Basel

0253-5068/16/0413-0166\$39.50/0
Andrew S. Bomback, MD, MPH

622 West 168th Street, PH 4-124

New York, NY 10032 (USA)

E-Mail asb68@columbia.edu 
disease [1-3], circumventing even dual prior RAAS blockade [1]. Although blockade of the RAAS has traditionally been performed with ACE inhibitors or ARBs, and more recently direct renin inhibitors have been tried [4], 30-50\% of patients on long-term therapy have unexpected elevations of serum aldosterone levels, a phenomenon termed 'aldosterone breakthrough' [4-7]. This paradoxical elevation in aldosterone levels in some ways mirrors animal studies in which aldosterone is infused over the background of ACE inhibitors or ARBs. This breakthrough leads to the progression of cardiac and renal disease, as ACE inhibitors and ARBs may not adequately block the MR component [8-11].

The phenomenon of aldosterone breakthrough, well described in the cardiac and renal literature $[4,7,8,12]$, may explain the mortality benefit of aldosterone blockade as add-on therapy to ACE inhibitors or ARBs in congestive heart failure (CHF) [13-15]. Following myocardial infarction, patients in the highest quartile of aldosterone levels have double the event rate of death, resuscitated cardiac arrest, recurrent or extended myocardial infarction, recurrent ischemia, CHF, and stroke [16]. Patients with systolic CHF who have aldosterone breakthrough despite ACE inhibition have significantly lower peak oxygen uptake and percent-predicted oxygen uptake [17]. In essence, this breakthrough may attenuate the end-organ benefits of RAAS blockade.

In healthy humans consuming variable quantities of dietary sodium, a reciprocal relationship exists between serum aldosterone concentration and daily urinary sodium excretion, a surrogate measure of extracellular volume (ECV). The physiological elevations in renin, angiotensin II, and aldosterone in response to low ECV states do not cause hypertension or vascular inflammation. In healthy individuals, angiotensin II is a primary regulator of aldosterone secretion, which, in turn, is regulated by renin released by the juxtaglomerular apparatus in response to changes in effective arterial blood volume. These homeostatic effects are mediated by the classical action of aldosterone on the MR located on epithelial cells of the distal convoluted tubule and cortical collecting duct.

Aldosterone levels, in relation to a cofactor of plasma renin activity, increase as GFR falls (fig. 1), and thus CKD and ESRD are considered states of relative hyperaldosteronism [18-20] in which aldosterone breakthrough may be particularly noxious. The inverse relationship between ECV and serum aldosterone concentration suggests that in the setting of low dietary sodium intake, levels of renin, angiotensin II, and aldosterone increase but do not cause inflammation and end-organ damage [21]. However,

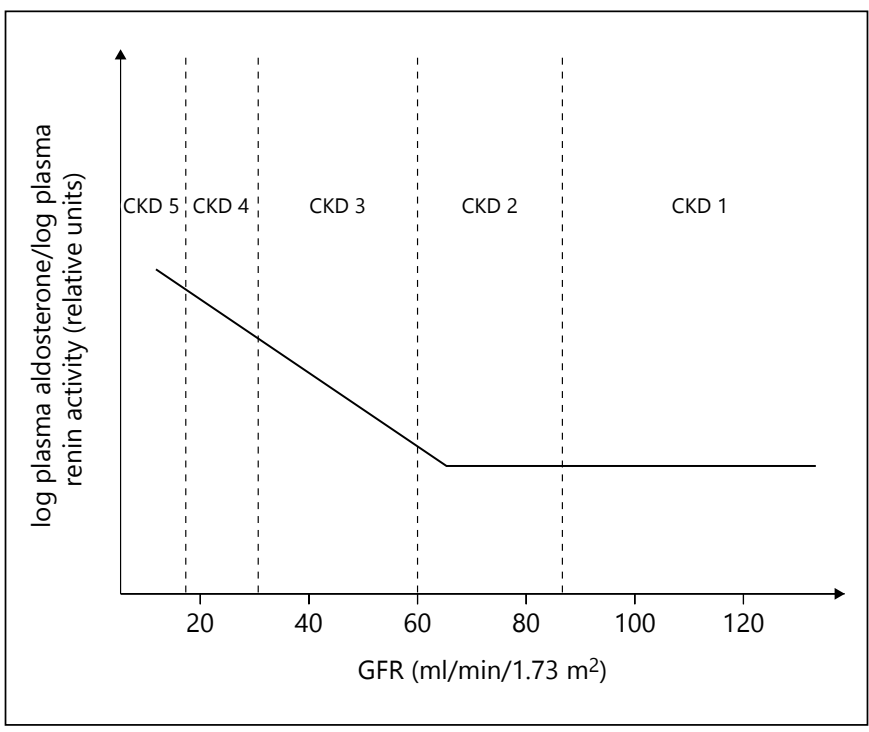

Fig. 1. Plasma aldosterone levels rise as GFR falls. In CKD stages 3-5, although ECV expansion manifests clinically as hypertension with or without edema, plasma aldosterone levels (in reference to a cofactor of plasma renin activity) rise, establishing CKD as a state of relative hyperaldosteronism. The degree of aldosteronism is most pronounced in CKD 5, marking the dialysis population as a prime target for aldosterone-targeted drugs. Based on data from Hené et al. [19].

CKD [22, 23] and ESRD [24] are notable states of relative hyperaldosteronism despite ECV expansion - that is, aldosterone levels are not sufficiently suppressed for the degree of ECV expansion (fig. 2) - leading to proinflammatory MR activation [22, 23, 25, 26]. In experimental studies, some of the adverse tissue effects of inappropriate MR activation occur at non-epithelial MR receptors, develop rapidly, are non-genomic, and have the potential to be attenuated by the use of MRAs.

\section{Efficacy of Aldosterone Antagonists in ESRD}

Spironolactone and eplerenone have become mainstays of treating CHF due to the large clinical trials, RALES and EPHESUS $[13,14]$. These MRAs have become increasingly used in proteinuric CKD management, but the evidence stems from smaller studies, many of which are uncontrolled [27, 28]. An even more modest literature exists on the use of MRAs in patients with ESRD. Two of the earliest, smallest studies confirmed a non-diuretic mechanism of MRAs in blood pressure control. In a double-blind, placebo-controlled RCT of 8 oligoanuric hemodialysis patients, spironolactone $50 \mathrm{mg}$ 


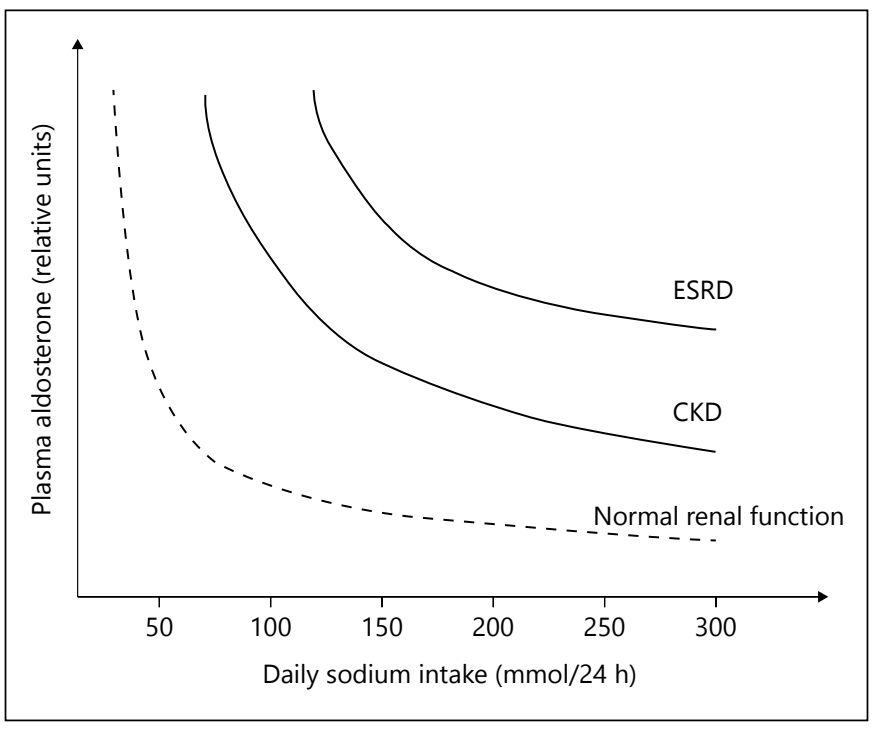

Fig. 2. Chronic and end-stage kidney disease are states of relative hyperaldosteronism. Increased sodium intake, and subsequent volume expansion, should suppress the renin angiotensin aldosterone system, with an inverse relationship between daily salt loads and plasma aldosterone concentrations. This relationship still exists as renal function declines, but aldosterone is inadequately suppressed in CKD and ESRD patients compared to individuals with preserved GFRs. This relative hyperaldosteronism creates a high aldosteronehigh sodium state that can activate non-epithelial mineralocorticoid receptors to produce inflammatory and fibrotic effects in the cardiovascular and renal systems. Adapted from Volk et al. [26].

twice daily led to a decline in pre-dialysis SBP from 142 to $131 \mathrm{~mm} \mathrm{Hg}$ [29]. In a similar cohort that was given eplerenone $25 \mathrm{mg}$ twice daily, pre-dialysis SBP dropped from 166 to $153 \mathrm{~mm} \mathrm{Hg}$ [30].

Targeting aldosterone in the CKD population should yield benefits beyond proteinuria and blood pressure reduction, given the numerous avenues of injury that aldosterone's actions have in the cardiovascular system, making ESRD patients a potentially prime target population for MRA therapy. The absolute mortality benefit for spironolactone in CHF appears highest among patients with CKD [31]. Similar reductions in CV morbidity and mortality should be seen in ESRD patients if treated with MRAs. In the CRIB-II study, spironolactone added to an ACE inhibitor for 10 weeks resulted in significant reductions in LVMI (11.4\%), left ventricular (LV) mass (11.8\%), and $\mathrm{LVH}$ prevalence $(50 \%)$, whereas the placebo-treated group showed no change [32]. ESRD patients typically have LVH, and LVMI correlates with aldosterone levels in non-diabetic patients on hemodialysis $[33,34]$. In a recent study of 328 hemodialysis patients, the median serum aldosterone level was $18.4 \mathrm{ng} / \mathrm{dl}$, and the highest ter- tile (level $>28 \mathrm{ng} / \mathrm{dl}$, as compared with level $<14 \mathrm{ng} / \mathrm{dl}$ ) was associated with a doubling of mortality and cardiovascular events in euvolemic patients [24].

In a small double-blind, placebo-controlled RCT of 11 hemodialysis patients with systolic CHF, those given spironolactone (25 $\mathrm{mg}$ thrice weekly after dialysis) for 6 months had a significant improvement in LV ejection fraction (mean absolute increase $6 \%$ vs. no change with placebo) and LV mass (mean decrease $8.4 \mathrm{~g} / \mathrm{m}^{2}$ vs. no change with placebo) [35]. In peritoneal dialysis subjects, spironolactone conferred similar benefits, with a $30 \%$ improvement in ejection fraction (and no benefit with placebo) after 6 months of therapy in an RCT [36]. A subsequent placebo-controlled study in hemodialysis patients without CHF found no improvement in echocardiographic measures after 4 months on spironolactone but showed significant improvement in endothelial function as measured by increased reactive hyperemia (from $80 \%$ at baseline to $152 \%$ on spironolactone) with prolonged duration ( 35 to $48 \mathrm{~s}$, respectively). Heart rate variability, a known mortality risk factor [37], was also significantly decreased [38].

Spironolactone given for 3 years attenuated vascular calcification as determined by aortic computed tomography in five hemodialysis patients [39]. Probing carotid intima-media thickness via ultrasonography in the carotid arteries, 53 non-diabetic, hemodialysis patients were followed for 2 years to examine the effect of MR activation on atherosclerosis progression. Spironolactone-treated patients (50 mg thrice weekly after dialysis) had statistically significant stabilization (5 of 6 areas evaluated) and even some improvement (left internal carotid artery, mean $1.15-0.84 \mathrm{~mm}$ ), while the placebo-treated group had diffuse progression over time in most areas [40].

\section{Safety of Aldosterone Antagonists in ESRD}

These small studies are important as much for their efficacy data as their safety signal. Although, in general, serum potassium levels rise with MRA administration in hemodialysis patients, only rarely does therapy lead to clinically meaningful hyperkalemia requiring medication or dialysate adjustments [41-43]. Patients on continuous ambulatory peritoneal dialysis [36] and continuous cycler-assisted peritoneal dialysis [44] have safely received spironolactone for systolic CHF without significant hyperkalemia.

A 6-month pilot study with the specific goal of determining the risk of hyperkalemia during spironolactone 
therapy was conducted in 50 Japanese, oligoanuric, chronic hemodialysis patients who did not have a hyperkalemic episode in the 2 months preceding the trial [45]. Pre-dialysis serum potassium was checked at baseline, 2 weeks, 4 weeks, 2 months and 6 months after administration of spironolactone $25 \mathrm{mg}$ daily. No changes were made during the trial in existing therapy with ACE inhibitors, ARBs, loop diuretics, cation exchange resins, dialysis prescription or dietary potassium restriction. Mean potassium levels increased from $4.96 \pm 0.72$ to $5.26 \pm 0.76 \mathrm{mEq} / \mathrm{l}$ during the study period, but no individual measurement was $>6.8 \mathrm{mEq} / \mathrm{l}$, nor was hyperkalemia a reason for stopping treatment with spironolactone. Development of gynecomastia in 3 patients led to study withdrawal.

The same authors have recently reported a prospective, randomized study in which 309 hemodialysis patients received spironolactone $25 \mathrm{mg}$ daily vs. no MRA therapy for 3 years [46]. The primary objective of this study was to gauge spironolactone's effect on cardiovascular and cerebrovascular mortality or hospitalization. The incidence of the primary outcome in the spironolactone cohort was $5.7 \%$ compared to $12.5 \%$ in the control cohort $(\mathrm{p}=0.017)$. The secondary outcome of death from all causes was similarly reduced in the treatment group, $6.4 \%$, compared to the non-MRA group, $19.7 \%$ ( $\mathrm{p}=$ 0.002 ). Hyperkalemia (defined as $>6.5 \mathrm{mEq} / \mathrm{l}$ ) occurred in $2 \%$ and gynecomastia in $10 \%$ of the spironolactone patients.

Currently, a randomized, placebo-controlled study of spironolactone in hemodialysis patients is in progress (ALdosterone Antagonist Chronic HEModialysis Interventional Survival Trial, ALCHEMIST), hoping to enroll more than 800 patients, with the primary endpoint of time until first nonfatal myocardial infarction or hospitalization for heart failure or nonfatal stroke or cardiovascular death. This study, in addition to providing the best evidence to date on MRA efficacy in the ESRD population, will provide crucial data on the safety of these agents in patients on dialysis.

\section{Conclusion}

Blocking aldosterone's classical and non-genomic actions using MRAs such as spironolactone and eplerenone is an important part of managing patients with CKD and CHF. Extending the use of these agents to the dialysis population appears beneficial from the small-scale studies that have been performed to date. Of equal importance, these studies have provided important and reassuring data about the safety of MRAs in dialysis patients. Larger trials of using MRAs in ESRD patients are currently underway and, if they confirm the results of these preliminary studies, could transform the standard of care in treating blood pressure and cardiovascular disease in ESRD.

\section{Acknowledgments}

None.

\section{Disclosure Statement}

No conflicts of interest to declare.

\section{References}

1 Greene EL, Kren S, Hostetter TH: Role of aldosterone in the remnant kidney model in the rat. J Clin Invest 1996;98:1063-1068.

2 Rocha R, Chander PN, Zuckerman A, Stier CT Jr: Role of aldosterone in renal vascular injury in stroke-prone hypertensive rats. Hypertension 1999;33(1 pt 2):232-237.

3 Rocha R, Stier CT Jr, Kifor I, et al: Aldosterone: a mediator of myocardial necrosis and renal arteriopathy. Endocrinology 2000;141: 3871-3878

4 Bomback AS, Rekhtman Y, Klemmer PJ, Canetta PA, Radhakrishnan J, Appel GB: Aldosterone breakthrough during aliskiren, valsartan, and combination (aliskiren + valsar$\tan$ ) therapy. J Am Soc Hypertens 2012;6: 338-345.
5 Sato A, Hayashi K, Naruse M, Saruta T: Effectiveness of aldosterone blockade in patients with diabetic nephropathy. Hypertension 2003;41:64-68.

6 Horita Y, Taura K, Taguchi T, Furusu A, Kohno S: Aldosterone breakthrough during therapy with angiotensin-converting enzyme inhibitors and angiotensin II receptor blockers in proteinuric patients with immunoglobulin A nephropathy. Nephrology (Carlton) 2006; 11:462-466.

7 Bomback AS, Klemmer PJ: The incidence and implications of aldosterone breakthrough. Nat Clin Pract Nephrol 2007;3:486492.

8 Struthers AD: Aldosterone escape during angiotensin-converting enzyme inhibitor thera- py in chronic heart failure. J Card Fail 1996;2: 47-54.

9 Naruse M, Tanabe A, Sato A, et al: Aldosterone breakthrough during angiotensin II receptor antagonist therapy in stroke-prone spontaneously hypertensive rats. Hypertension 2002;40:28-33.

10 Lakkis J, Lu WX, Weir MR: RAAS escape: a real clinical entity that may be important in the progression of cardiovascular and renal disease. Curr Hypertens Rep 2003;5:408-417.

11 Schjoedt KJ, Andersen S, Rossing P, Tarnow $\mathrm{L}$, Parving $\mathrm{HH}$ : Aldosterone escape during blockade of the renin-angiotensin-aldosterone system in diabetic nephropathy is associated with enhanced decline in glomerular filtration rate. Diabetologia 2004;47:1936-1939. 
12 Pitt B: 'Escape' of aldosterone production in patients with left ventricular dysfunction treated with an angiotensin converting enzyme inhibitor: implications for therapy. Cardiovasc Drugs Ther 1995;9:145-149.

13 Pitt B, Zannad F, Remme WJ, et al: The effect of spironolactone on morbidity and mortality in patients with severe heart failure. Randomized aldactone evaluation study investigators. N Engl J Med 1999;341:709-717.

14 Pitt B, Remme W, Zannad F, et al: Eplerenone, a selective aldosterone blocker, in patients with left ventricular dysfunction after myocardial infarction. N Engl J Med 2003; 348:1309-1321.

15 Zannad F, McMurray JJ, Krum H, et al: Eplerenone in patients with systolic heart failure and mild symptoms. N Engl J Med 2011;364:11-21.

16 Beygui F, Montalescot G, Vicaut E, et al: Aldosterone and long-term outcome after myocardial infarction: a substudy of the French nationwide observatoire sur la prise en charge hospitalière, l'Evolution à un an et les caRactéristiques de patients présentant un infArctus du myocarde avec ou sans onde Q (OPERA) study. Am Heart J 2009;157:680687.

17 Cicoira M, Zanolla L, Franceschini L, et al: Relation of aldosterone 'escape' despite angiotensin-converting enzyme inhibitor administration to impaired exercise capacity in chronic congestive heart failure secondary to ischemic or idiopathic dilated cardiomyopathy. Am J Cardiol 2002;89:403-407.

18 Berl T, Katz FH, Henrich WL, de Torrente A, Schrier RW: Role of aldosterone in the control of sodium excretion in patients with advanced chronic renal failure. Kidney Int 1978; 14:228-235.

19 Hené RJ, Boer P, Koomans HA, Mees EJ: Plasma aldosterone concentrations in chronic renal disease. Kidney Int 1982;21:98-101.

20 Reams GP, Bauer JH: Effect of enalapril in subjects with hypertension associated with moderate to severe renal dysfunction. Arch Intern Med 1986;146:2145-2148.

21 Bomback AS, Klemmer PJ: Mineralocorticoid receptor blockade in chronic kidney disease. Blood Purif 2012;33:119-124.

22 Bomback AS, Kshirsagar AV, Ferris ME, Klemmer PJ: Disordered aldosterone-volume relationship in end-stage kidney disease. J Renin Angiotensin Aldosterone Syst 2009;10: 230-236.

23 Schrier RW, Masoumi A, Elhassan E: Aldosterone: role in edematous disorders, hypertension, chronic renal failure, and metabolic syndrome. Clin J Am Soc Nephrol 2010;5: 1132-1140.
24 Hung SC, Lin YP, Huang HL, Pu HF, Tarng DC: Aldosterone and mortality in hemodialysis patients: role of volume overload. PLoS One 2013;8:e57511.

25 Bomback AS, Klemmer PJ: Interaction of aldosterone and extracellular volume in the pathogenesis of obesity-associated kidney disease: a narrative review. Am J Nephrol 2009;30:140-146.

26 Volk MJ, Bomback AS, Klemmer PJ: Mineralocorticoid receptor blockade in chronic kidney disease. Curr Hypertens Rep 2011;13: 282-288.

27 Bomback AS, Kshirsagar AV, Amamoo MA, Klemmer PJ: Change in proteinuria after adding aldosterone blockers to ACE inhibitors or angiotensin receptor blockers in CKD: a systematic review. Am J Kidney Dis 2008;51: 199-211.

28 Navaneethan SD, Nigwekar SU, Sehgal AR, Strippoli GF: Aldosterone antagonists for preventing the progression of chronic kidney disease. Cochrane Database Syst Rev 2009, 3:CD007004.

29 Gross E, Rothstein M, Dombek S, Juknis HI: Effect of spironolactone on blood pressure and the renin-angiotensin-aldosterone system in oligo-anuric hemodialysis patients. Am J Kidney Dis 2005;46:94-101.

30 Shavit L, Neykin D, Lifschitz M, Slotki I: Effect of eplerenone on blood pressure and the renin-angiotensin-aldosterone system in oligo-anuric chronic hemodialysis patients - a pilot study. Clin Nephrol 2011;76:388-395.

31 Vardeny O, Wu DH, Desai A, et al: Influence of baseline and worsening renal function on efficacy of spironolactone in patients with severe heart failure: insights from RALES (randomized aldactone evaluation study). J Am Coll Cardiol 2012;60:2082-2089.

32 Edwards NC, Steeds RP, Stewart PM, Ferro CJ, Townend JN: Effect of spironolactone on left ventricular mass and aortic stiffness in early-stage chronic kidney disease: a randomized controlled trial. J Am Coll Cardiol 2009; 54:505-512.

33 Sato A, Funder JW, Saruta T: Involvement of aldosterone in left ventricular hypertrophy of patients with end-stage renal failure treated with hemodialysis. Am J Hypertens 1999;12(9 pt 1):867-873.

34 Steigerwalt S, Zafar A, Mesiha N, Gardin J, Provenzano R: Role of aldosterone in left ventricular hypertrophy among AfricanAmerican patients with end-stage renal disease on hemodialysis. Am J Nephrol 2007;27: 159-163.
35 Taheri S, Mortazavi M, Shahidi S, et al: Spironolactone in chronic hemodialysis patients improves cardiac function. Saudi J Kidney Dis Transpl 2009;20:392-397.

36 Taheri S, Mortazavi M, Pourmoghadas A, Seyrafian S, Alipour Z, Karimi S: A prospective double-blind randomized placebo-controlled clinical trial to evaluate the safety and efficacy of spironolactone in patients with advanced congestive heart failure on continuous ambulatory peritoneal dialysis. Saudi J Kidney Dis Transpl 2012;23:507512.

37 Fukuta H, Hayano J, Ishihara S, et al: Prognostic value of heart rate variability in patients with end-stage renal disease on chronic haemodialysis. Nephrol Dial Transplant 2003;18: 318-325.

38 Flevari P, Kalogeropoulou S, Drakou A, et al: Spironolactone improves endothelial and cardiac autonomic function in non heart failure hemodialysis patients. J Hypertens 2013;31: 1239-1244.

39 Nitta K, Akiba T, Nihei H: Aldosterone blockade and vascular calcification in hemodialysis patients. Am J Med 2003;115:250.

40 Vukusich A, Kunstmann S, Varela C, et al: A randomized, double-blind, placebo-controlled trial of spironolactone on carotid intima-media thickness in nondiabetic hemodialysis patients. Clin J Am Soc Nephrol 2010;5:13801387.

41 Chua D, Lo A, Lo C: Spironolactone use in heart failure patients with end-stage renal disease on hemodialysis: is it safe? Clin Cardiol 2010;33:604-608.

42 Baker WL, White WB: Safety of mineralocorticoid receptor antagonists in patients receiving hemodialysis. Ann Pharmacother 2012; 46:889-894.

43 Rekhtman Y: Mineralocorticoid receptor-associated hypertension and target organ damage: clinical relevance for resistant hypertension in end stage renal disease. Curr Hypertens Rev 2012;8:267-275.

44 Hausmann MJ, Liel-Cohen N: Aldactone therapy in a peritoneal dialysis patient with decreased left ventricular function. Nephrol Dial Transplant 2002;17:2035-2036.

45 Matsumoto Y, Kageyama S, Yakushigawa T, et al: Long-term low-dose spironolactone therapy is safe in oligoanuric hemodialysis patients. Cardiology 2009;114:32-38.

46 Matsumoto Y, Mori Y, Kageyama S, et al: Spironolactone reduces cardiovascular and cerebrovascular morbidity and mortality in hemodialysis patients. J Am Coll Cardiol 2014; 63:528-536. 